\section{¿Por qué hacen huelga los internos de Medicina en Perú?}

\section{Why do pre graduate medical interns go into strike in Perú?}

\section{Sr. Editor:}

El internado médico es una etapa en la que el estudiante de medicina consolida e integra los conocimientos adquiridos en años previos de su carrera ${ }^{1}$. A pesar de la importancia del internado en la formación médica, existen problemas que impiden su adecuado desarrollo, como carencias de áreas de descanso, de equipos de bioseguridad, de las remuneraciones acordadas, entre otros ${ }^{2}$.

Ante estos problemas, los internos de medicina han elevado su voz de protesta, llegando incluso a realizar interrupciones colectivas de su actividad laboral, conocidas como huelgas. De esta manera se tiene información sobre huelgas de internos en varios países de Latinoamérica: Honduras ${ }^{3}$, Chile C Costa Rica $^{4}$.

Estas huelgas traen como consecuencia una carencia de personal que perjudica la atención de los pacientes. Además, se interrumpe la actividad académica del interno, afectando su preparación en este período clave ${ }^{6}$. Por ello, es importante conocer las características de estas huelgas, lo cual permitirá prevenirlas en el futuro.

Con el fin de identificar las huelgas de internos en Perú, durante septiembre de 2015 se realizaron búsquedas en Google y Facebook, empleando los términos: [huelga Perú internado médico] y [huelga Perú internos]. Se realizaron entrevistas a internos o médicos de cada Facultad de Medicina Humana del Perú que hayan realizado el internado durante el período 2012-2015, contactados mediante la Sociedad Científica Médico Estudiantil Peruana. Una vez identificadas las huelgas, se contactó los participantes por teléfono o Facebook, para recolectar los datos correspondientes.

Encontramos información de cuatro huelgas entre el año 2013 y octubre de 2015 (Tabla 1), aunque probablemente este sea un sub registro, debido a la metodología utilizada. Dos de las huelgas se presentaron fuera de Lima. Las cuatro se realizaron en hospitales del Ministerio de Salud del Perú (MINSA). En la búsqueda realizada en Google sólo se encontraron notas periodísticas de dos huelgas, lo cual indica que estas acciones de protesta no lograron una difusión mediática.

Las causas de estas huelgas fueron: incumplimiento de pago; incumplimiento del derecho de alimentación; y apoyo a una huelga de médicos. Esto reflejaría el frágil estado económico de algunos internos, cuya subsistencia depende del pago y la alimentación que se les brinda.

En los hospitales del MINSA no todos los internos reciben un pago y, cuando lo reciben, éste suele ser de S/.400 nuevos soles (equivalentes a US\$125) al mes.

Lamentablemente, los documentos reguladores del internado médico en Perú (Decreto Supremo N ${ }^{\circ} 003-$ 2008 y Reglamento Nacional del Comité de SINAPRES) no estipulan el pago que debe recibir un interno, a pesar de ser una práctica pre-profesional de tiempo completo y con gran riesgo laboral.

En las huelgas encontradas, participaron de 20 a 53 internos, durante algunos días o semanas. En todos los casos se consiguió el logro total o parcial del beneficio reclamado, demostrándose que la huelga ha sido una medida de fuerza drástica pero efectiva. 
Tabla 1. Huelgas de Internos de Medicina en Perú (2013-2015) (Todas en dependencias del Ministerio de Salud del Perú)

\begin{tabular}{|c|c|c|c|c|c|}
\hline Departamento & Año & Causas & $\begin{array}{l}\text { Número de } \\
\text { internos } \\
\text { participantes } \\
\text { (aproximado) }\end{array}$ & Duración & Resultado \\
\hline Trujillo & 2013 & $\begin{array}{l}\text { Incumplimiento del derecho de } \\
\text { alimentación hacia los internos en } \\
\text { sede hospitalaria }\end{array}$ & 49 & 3 semanas & $\begin{array}{l}\text { Se brindó alimentación } \\
\text { después de concluida } \\
\text { la huelga }\end{array}$ \\
\hline Huancayo & 2014 & $\begin{array}{l}\text { Aumento de sueldos para médicos, } \\
\text { reducción de tiempos en compra } \\
\text { de medicamentos y contratación de } \\
\text { personal suficiente para satisfacer } \\
\text { la demanda }\end{array}$ & $\begin{array}{l}\text { 30, en apoyo a } \\
\text { los médicos }\end{array}$ & 5 semanas & $\begin{array}{l}\text { Aumento de sueldos } \\
\text { para médicos de } \\
\text { EsSalud }\end{array}$ \\
\hline Lima & 2015 & $\begin{array}{l}\text { Incumplimiento de pago a internos } \\
\text { por } 7 \text { meses laborales }\end{array}$ & 20 & 3 días & $\begin{array}{l}\text { Pago parcial de meses } \\
\text { laborados }\end{array}$ \\
\hline Lima & 2015 & $\begin{array}{l}\text { Incumplimiento de pago hacia } \\
\text { internos }\end{array}$ & 53 & 1 día & $\begin{array}{l}\text { Pago total de meses } \\
\text { laborados }\end{array}$ \\
\hline
\end{tabular}

El internado de medicina en el Perú, al igual que en otros países de Latinoamérica, presenta varios problemas, y las huelgas expuestas reflejan sólo la punta de este iceberg. Por lo cual resulta necesario estudiar esta problemática y proponer intervenciones por el bien de los internos y de sus pacientes.

\section{Wendy Nieto-Gutiérrez ${ }^{1, a}$, Guido Bendezú-Quispe ${ }^{2, a}$, Álvaro Taype-Rondan ${ }^{3, b}$ \\ ${ }^{1}$ Sociedad Científica de Estudiantes de Medicina de la Universidad de San Martín de Porres, Universidad de San Martín de Porres, Lima, Perú. \\ ${ }^{2}$ Sociedad Científica de Estudiantes de Medicina de Ica, Universidad Nacional San Luis Gonzaga, Ica, Perú. ${ }^{3}$ CRONICAS Centro de Excelencia en Enfermedades Crónicas, Universidad Peruana Cayetano Heredia, Lima, Perú. ${ }^{a}$ Estudiante de Medicina Humana. ${ }^{b}$ Médico-Cirujano.}

\section{Referencias}

1. ASPEFAM. Asociación de estudiantes de Medicina. Reglamento del Comité Nacional de Pregrado de Salud del SINAPRES. 2006.

2. Comité Médico Joven. Características del internado médico en el Perú. 2010.

3. El Heraldo. Huelgas de estudiantes de medicina. 14 de abril de 2012; Recuperado a partir de: http://www.elhe-
raldo.hn/csp/mediapool/sites/ElHeraldo/Pais/story.csp?ci$\mathrm{d}=569869 \&$ sid $=299 \&$ fid $=214$.

4. Diario La Nación. Huelga de internos de Medicina USACh en el Hospital San José. 2012 [citado el 25 de agosto de 2015]; Recuperado a partir de: http://www.lanacion.cl/huelga-de-internos-de-medicina-usach-en-el-hospital-san-jose/ noticias/2012-09-14/115242.html.

5. Internos se mantienen en huelga en las afueras del Calderón Guardia. CRHoy.com | Periodico Digital | Costa Rica Noticias 24/7 [Internet]. 2013 [citado 25 de agosto de 2015]; Recuperado a partir de: http://www.crhoy.com/ internos-se-mantienen-en-huelga-en-las-afueras-del-calderon-guardia/

6. Carrillo-Larco RM, Taype-Rondán Á, Pereyra-Elías R. Does physicians' right to strike outweigh students' right to an education? The on-going ethical dilemma in Peru. Med Educ Online [Internet]. 19 de diciembre de 2012 [citado el 29 de agosto de 2015]; 17. Recuperado a partir de: http:// www.ncbi.nlm.nih.gov/pmc/articles/PMC3527587/

Conflictos de intereses: ninguno que declarar.

Correspondencia a:

Wendy Nieto Gutiérrez

Teléfono: 995735173

wendy_nieto22@hotmail.com 